\title{
Habitat evaluation and conservation framework of the newly discovered and critically endangered black \\ snub-nosed monkey
}

Guo-Peng Ren ${ }^{\mathrm{a}, \mathrm{cl}}$,Yin Yang ${ }^{\mathrm{a}, \mathrm{b}, \mathrm{c} 1}$, Xiao-Dong $\mathrm{He}^{\mathrm{c}, \mathrm{d}}$, Guang-Song $\mathrm{Li}^{\mathrm{c}, \mathrm{d}}$, Ying Gao ${ }^{\mathrm{a}, \mathrm{c}}$, Zhi-Pang Huang ${ }^{\text {a,c }}$, Chi Ma ${ }^{\text {a,c }}$, Wei Wang ${ }^{e^{*}}$,Wen Xiao ${ }^{\text {a,c* }}$

${ }^{\mathrm{a}}$ Institute of Eastern-Himalaya Biodiversity Research, Dali University, Dali, Yunnan 671003, China

${ }^{\mathrm{b}}$ School of Archaeology \& Anthropology, Australian National University, Canberra, ACT 0200, Australia

${ }^{c}$ Collaborative Innovation Centre for Biodiversity and Conservation in the Three Parallel Rivers Regionof China, Dali, Yunnan 671003, China

${ }^{\mathrm{d}}$ Nujiang Bureau of Gaoligongshan National Nature Reserve, Nujiang, Yunnan 673100, China

${ }^{\text {e }}$ State Key Laboratory of Environmental Criteria and Risk Assessment, Chinese Research Academy of Environmental Sciences, Beijing 100012 China

${ }^{1}$ Joint first authors/these authors contributed equally to this work

* Corresponding authors at:

Institute of Eastern-Himalaya Biodiversity Research, Dali University, Dali, Yunnan 671003, China. Email address: xiaow@eastern-himalaya.cn (W.Xiao);

State Key Laboratory of Environmental Criteria and Risk Assessment, Chinese Research Academy of Environmental Sciences, Beijing 100012 China (W.Wang). 


\section{Abstract}

The black snub-nosed monkey (Rhinopithecus strykeri) is an IUCN-Critically Endangered primate, recently discovered on the northern Sino-Myanmar border. In order to identify the most urgent gaps in the conservation of the black snub-nosed monkey, a hierarchical process was employed to predict the distribution and alterations in its habitat over the past 15 years. Our study showed that $R$. strykeri appeared to inhabit a range from E98 $20^{\prime}-98^{\circ} 50^{\prime}, \mathrm{N} 25^{\circ} 40^{\prime}-26^{\circ} 50^{\prime}$, including high quality habitat at $1420 \mathrm{~km}^{2}$, medium quality habitat at $750 \mathrm{~km}^{2}$, and low quality habitats at $1410 \mathrm{~km}^{2}$. Only $21.1 \%$ of the total habitat for $R$. strykeri is within protected areas in China. Approximately $2.6 \%$ of the entire habitat has been lost in the past 15 years, $96 \%$ of which has been in Myanmar. To save this species from extinction, it is urgent to establish trans-boundary conservation and management networks to address the loss of habitat, and to locate and preserve key wildlife corridors to link fragmented habitats between Myanmar and China.

Key words: Rhinopithecus strykeri, habitat alterations, trans-boundary conservation, species distribution model 


\section{Introduction}

The recently described black snub-nosed monkey (Rhinopithecus strykeri), alternatively known as the Myanmar or Nujiang snub-nosed monkey, is found in the high altitude forests of north-eastern Kachin state, Myanmar (Geissmann et al., 2011) as well as in the middle segment of the Gaoligong Mountains, Yunnan, China (Long et al., 2012; Yang et al., 2016). There are up to 14 groups (10 in China and 4 in Myanmar, < 950 individuals) of black snub-nosed monkeys living in the northern Sino-Myanmar border area according to interviews (Geissmann et al., 2011; Ma et al., 2014). As a slow breeding species, combined with the prevalence of hunting and the extensive loss of habitat, this species is likely experiencing a rapid demographic decline (Geissmann et al., 2011). With the booming economy and population growth of the region, deforestation for agricultural cultivation and infrastructure development pose potential perils to this IUCN-Critically Endangered primate.

To save this species from the brink of extinction, it is important to study its habitat and its distribution, but, due to the extreme ruggedness of the terrain and the long wet season, almost no information on population distribution and habitat status are available for conservation planning. Where the data are poor in given study areas, employing MAXENT can offer reliable assessments for a species' possible distribution, and can support conservation planning (Thorn et al., 2009; Peck et al., 2011; Ingberman et al., 2016) by prioritizing appropriate habitats for new protected areas (Urbina-Cardona \& Loyola, 2008; Campos \& Jack, 2013) or guiding prospective land use planning and management (Illera et al., 2010), by identifying least-cost corridors for habitat connectivity (Liu et al., 2016; Luo et al., 2016; Schaffer-Smith et al., 2016), and by pinpointing ideal reintroduction sites (Thorn et al., 2009; Cilliers et al., 2013). The function of MAXENT is to generate a model across one study area based on existing information concerning environmental variables which is then used in another area to make predictions and inference of maximum entropy occurrence under similar environmental constraints (Phillips \& 
Dudík, 2008; Thorn et al., 2009; Araújo \& Peterson, 2012). Compared to other ecological niche algorithms, MAXENT as a present-only model can moderately offset for imperfect, limited species occurrence data sets and reach near-maximum accuracy levels under these circumstances (Hernandez et al., 2006, 2008; Giovanelli et al., 2010).

Based on climatic variables and two sets of locality records obtained by interview-based survey (Gessiman et al. 2011; Ma et al. 2014; Figure 1), a MAXENT model was built up to map the habitat of $R$. strykeri. Forest cover maps in the 2000s and 2015, based on Landsat images, were used to mask out non-woodland areas from the habitat. We then assessed habitat changes from 2000 to 2015. According to the results, we identified additional areas where $R$. strykeri may occur, proposed specific conservation priorities, and determined crucial areas in which urgent protection measures should be taken to ensure the long survival of this rare and little known primate.

\section{Methods}

\subsection{Study area}

The Gaoligong Mountains rise from the low altitude $(183 \mathrm{~m})$ drainage of the N'mai River in Myanmar to an altitude of $6318 \mathrm{~m}$ in the southeast of Zayü County (Chaplin, 2005). The altitudinal gradient yields a vertical zonation of climate, soil composition and solar radiation, generating diverse vegetation types and a rich flora and fauna diversity (ibid). The vegetation in the Gaoligong Mountains, from the valleys to the peaks, goes from tropical monsoon forest (< $1000 \mathrm{~m}$ a.s.1.), monsoon evergreen broad-leaved forest (1100-1800 m), semi moist evergreen broad-leaved forest (1700-2500 m) and mid-montane moist evergreen broad-leaved forest above (1900-2800 m), coniferous broadleaved mixed forest (2700-3500 m), to the alpine bush zone (> $3400 \mathrm{~m}$ ) (Li et al., 2000). 
According to Geissmann et al. (2011) and Ma et al. (2014), the known and potential $R$. strykeri populations are restricted to a narrow range of $98^{\circ} 20^{\prime}-98^{\circ} 49^{\prime} \mathrm{E}$, $25^{\circ} 58^{\prime}-26^{\circ} 31^{\prime} \mathrm{N}$. Two insurmountable natural barriers, the N 'Mai Hka and Salween Rivers, would appear to have physically blocked their expansion to other areas. Thus, the study area for this project ranged from the China State Road 320 (named Road NH3 in Myanmar) in the south to the provincial border between Yunnan and the Tibet Autonomous Region in the north, and from the N' Mai Hka River in the west to the Salween River in the east, with a total area of about $41,350 \mathrm{~km}^{2}$ (97.05-98.91E, 24.02-28.40N, Fig. 1).

\subsection{Species Occurrence Extraction}

Interview-based survey can cost-effectively and statistically access the number and distribution of rare and poorly known large animals, especially in the case of primates with a distinctive appearance such as the black snub-nosed monkey (Meijaard et al., 2011; Cui et al., 2015; Ma et al. 2015; Turvey et al. 2015). Between April 2011 and December 2012, our research mission visited 68 villages near the high-altitude forests and interviewed 358 old hunters or mountain villagers who entered the forests frequently in Gongshan, Fugong and Lushui counties, on the west bank of the Salween River in China (Ma et al., 2014). As a result, a total of 72 valid distributional records was obtained from 67 respondents, and two groups of black snub nosed monkeys then were confirmed in Pianma (Ma et al. 2014) and Luoma (Yang et al., 2016). These 72 records, which were further merged into 46 polygons with sizes ranging from 16 to 1727 ha, were used as species occurrence data in China since $R$. strykeri is not easily mistaken for any other primate given its peculiar appearance (Fig.1). Three possible distribution records reported by Geissmann et al. (2011) in the Maw River areas of Myanmar, with areas of 3854 ha, 4126 ha, and 6108 ha, were also included in the species occurrence data. 


\subsection{Data acquisition}

Data on both climate and vegetation were used to predict the distribution of the black snub-nosed monkey. Thirty two Landsat ETM+/OLI images were downloaded from USGS Earth Explorer (http://earthexplorer.usgs.gov/) to map forest cover over the study area (See Tab. A.1 in Supporting Information). Climatic data which we used include monthly maximum, minimum and mean temperature, monthly precipitation, and 19 variables (see Tab. A.2). All these climatic data were acquired from the WorldClim (http://www.worldclim.org, see Hijmans et al. 2005). As with the Landsat images, the WorldClim (30 arcsec spatial resolution, equal to $0.00833^{\circ}$ ) were transformed to a Universal Transverse Mercator coordinate system (UTM, WGS84 datum, Zone 47N) and spatially interpolated to $30 \mathrm{~m}$ resolution using bilinear interpolation.

\subsection{Forest mapping}

510 sets of $30 \times 30 \mathrm{~m}$ squares ( 9 squares per set) were systematically sampled as "ground-truth data" from the study area by visual interpretation of high resolution images on Google Earth (Google Inc, Tab. 1, Fig. A.1). Each square was deemed woodland if the tree cover was higher than $40 \%$; otherwise, it was determined as non-woodland. The whole project area was divided into woodland area and non-woodland area, based on Landsat TM/ETM+/OLI images (resolution $=30 \mathrm{~m}$ ) using a random forest algorithm with the "ground-truth data" (Breiman, 2001). The classification process was implemented using $\mathrm{R}$ Statistics software (http://www.r-project.org/) with the Random Forest package (Liaw \& Wiener, 2002) and Raster package (Hijmans, 2016).

\subsection{Species distribution modelling}

MAXENT is a popular species distribution model, with a history of superior performance (Boubli \& Lima, 2009; Thorn et al., 2009; Peck et al., 2011; Chetan et 
al., 2014; Hernandez et al. 2006; 2008). Species occurrence sites and environmental data are required to build a MAXENT model. At first, 10,000 pixels (30 m resolution) were randomly selected from the study area as background data (pseudo-absence data), 2000 samples of which were used as pseudo-absence data for the MAXENT model, and the remaining 8000 samples were used for validation. Two thirds of the species occurrence records, 33 of 49 distribution polygons, were randomly selected as a training polygon, and the remaining 16 polygons were used as test polygons. All the 49 distribution polygons were aggregated and rasterized at $30 \mathrm{~m}$ resolution. No more than 100 pixels or 50 percent of the total pixels were systematically sampled from each of the 49 distribution polygons. In total, 2772 samples were obtained from the 33 training polygons, and 1008 samples were obtained from the test polygons as test data.

A MAXENT model was built with the 2772 presence samples and 2000 background samples based on the 67 climate variables with the default parameters setting in the $\mathrm{R}$ package dismo (Hijmans et al. 2016). As a result, we obtained a climatic suitability layer of the study area. Four levels of climatic suitability were quantified according to relevant parameters of the MAXENT model for indentifying core, medium, low quality and none habitat (Tab. 2).

The Black snub-nosed monkey is arboreal and inhabits mainly subtropical broad-leafed forest and mixed temperate forest. Forests provide shelter and ample food for them; non-woodland areas could, therefore, be regarded as non-habitat. We obtained habitat maps in both stages (2000s and 2015s) by masking out non-woodland areas from the climatic suitability layer using forest cover maps. Habitat changing from 2000 to 2015 was estimated by simply comparison of the habitat maps in 2000 and 2015.

The AUC (area under curve) of ROC (receiver operating characteristic curves) was employed to measure the accuracies of the habitat maps. The AUC values were 0.964 and 0.957, which indicated that our habitat evaluation models were accurate (Araújo et al., 2005) 
All the above procedures were performed using R Statistics software (version 3. 3. 1, R Development Core Team, 2016) with some key packages, such as raster (Hijmans, 2016) and dismo (Hijmans et al. 2016).

\section{Results}

\subsection{Habitat distribution for the black snub-nosed monkey}

Based on results generated from the hierarchical model, the current geographical distribution for $R$. strykeri is predicted to be in the range of $E 98^{\circ} 20^{\prime}-98^{\circ} 50^{\prime}$, $\mathrm{N} 25^{\circ} 40^{\prime}-26^{\circ} 50^{\prime}$, with a total area of approximately $3575 \mathrm{~km}^{2}$, of which the core habitat is $1420 \mathrm{~km}^{2}$, medium quality habitat is $750 \mathrm{~km}^{2}$, and low quality habitats are $1405 \mathrm{~km}^{2}$ (Fig. 2). Among these suitable habitats, $2444 \mathrm{~km}^{2}(68.4 \%)$ are in Myanmar, and $1131 \mathrm{~km}^{2}(31.6 \%)$ in China. Only $21.1 \%$ of the total habitat is located in existing protected areas of China. The largest patch of core habitat harboring most $R$. strykeri groups covered $1280 \mathrm{~km}^{2}$ and crossed the China-Myanmar border within a range of $50 \mathrm{~km}$, including $450 \mathrm{~km}^{2}(35.2 \%)$ in China and $830 \mathrm{~km}^{2}(64.8 \%)$ in Myanmar. The vertical range of core habitat is estimated to be 2330 to $3240 \mathrm{~m}$ in both countries.

\subsection{Habitat alterations in the past fifteen years}

In 2000 there was an estimated $3670 \mathrm{~km}^{2}$ of habitat in the Sino-Myanmar border region, but by 2015 this figure had declined by $95 \mathrm{~km}^{2}$ (a destruction of $2.6 \%$ over time or a mean of $0.17 \% \mathrm{yr}^{-1}$ ). Correspondingly, the core, medium and low quality habitats decreased by $50,20,25 \mathrm{~km}^{2}$. Of the total habitat loss, $96 \%$ was in northern Myanmar. The loss of habitat within Myanmar from 2000 to 2015 was estimated to be $97 \mathrm{~km}^{2}$, or $3.8 \%$ of the entire habitat of the species in Myanmar for the year 2000 (Fig. 3), while in China, forest cover loss $\left(4 \mathrm{~km}^{2}\right)$ was lower than the amount of 
forest rehabilitation $\left(6 \mathrm{~km}^{2}\right)$; the destruction occurred mostly outside the Gaoligong Mountains National Nature Reserve.

\section{Discussion}

\subsection{Urgent conservation needs and applications}

In general, the entire habitat area was reduced between 2000 and 2015, although the overall speed of loss and recovery was irregular (Fig. 3). In Myanmar, R. strykeri faces intense pressure from habitat loss and hunting, as there are no conservation measures to date. Habitat loss is due not only to shifting cultivation near human settlements in the valley, but also extends along criss-crossing roads because of commercial logging, dam construction and mining into the central core habitat area, and even peaks (Momberg et al., 2010; Geissmann et al., 2012), which may have affected population continuity because of habitat fragmentation and disruption of habitat connectivity (See Fig. 3, right images). In addition, hunting of this species is still very severe, even after the species' discovery in 2010 (Meyer et al., 2015); combined with habitat loss it is projected that this may lead to a species decline of more than $80 \%$ in the next fifteen years in Myanmar (Geissmann et al., 2012). In China, more than half of the habitat $\left(753 \mathrm{~km}^{2}, 66.6 \%\right)$ is located outside the reserve and there has been depletion of forest resources caused by human population growth. Occasionally hunting for bush meat and traditional medicine has provided further pressure (Ma et al., 2014; Fig. A.2.F). Considering all these factors, we propose the three following major conservation procedures:

First, conservation gaps should be filled by the establishment of new protected areas (Fig. 2). The habitat of $R$. strykeri slightly recovered in the Gaoligong Mountains National Nature Reserve, and this indicates that the creation of new protected areas might be an efficient method to maintain the habitat in this region. Long et al. (2012) recommended Sino-Myanmar cooperation in delineating a trans-boundary wildlife 
sanctuary to protect this species. Support by the relevant institutions, the Myanmar Ministry of Environmental Conservation and Forestry and the National Democratic Army of Kachin (a pro-government militia), has already led to agreement to create a protected area, named Imawbum National Park, in Sawlaw Township (pers. comm. Fauna \& Flora International, 2016). We propose that the range of Imawbum National Park should border the Gaoligong Mountains National Nature Reserve in China (see Fig. 2), which covers an area of $1934 \mathrm{~km}^{2}$. At present, the proclamation of new national parks in China is proceeding rapidly. The Program for National Park Development in Yunnan Province 2009-2020 under the Yunnan Provincial Government proposed to create a national park in Nujiang Autonomous Prefecture. We hence suggest setting up the range of Gaoligong Mountains National Park $\left(328 \mathrm{~km}^{2}\right)$ to link the southern and central segments of the Giaoligong Mountains National Nature Reserve in Lushui County (Fig. 2).

Second, management plans need to consider the linkages between the protected areas on both sides of the border and the importance of maintaining habitat corridors that presently connect them. Based on the habitat distribution pattern, two wildlife corridors with management measures are proposed here to contribute habitat connection and connectivity maintenance. In particular, the most important trans-boundary habitat corridor should be located in the northern edge of the fragmented habitats to connect the two largest core habitats in Myanmar (Fig. 2, black circled area $\mathrm{C} 1$ ) in order to enable population dispersal and gene flow and increase the probability of the species' persistence. Timber extraction, shifting cultivation and road construction are imminent threats to this corridor. Any further deforestation should be prohibited there, and the lost habitats must be speedily restored by natural rehabilitation. We subsequently propose that the remaining vegetation in Myanmar must be strictly protected where the area borders the habitat at Gangfang Village of Pianma Township in China (Fig. 2, black circled area C2). The habitat there was dramatically disjointed by commercial harvesting, shifting cultivation, road construction and mining; a small cross-border population, however, 
may inhabit this general area (Ma et al., 2010; a newly dead adult female specimen was collected from a hunter in Gangfang of Myanmar in November, 2015). Natural recovery assisted by artificial restoration of trees in this area will quickly restore a habitat corridor on the Sino-Myanmar border and increase the chances for survival for the threatened population.

Third, we urgently recommend a Sino-Myanmar joint-patrol law enforcement team for implementation of the trans-boundary zoning and management plan to combat hunting and illegal trans-boundary logging activities. Thus, we can ensure that effective National Park management will be in place and that both forest departments can enforce the law against hunting and illegal logging in the border area, and to avoid a "paper park" becoming established like many others in Myanmar (see Rao et al., 2002; Aung, 2007). As the Sino-Myanmar border is a relatively poor and backward remote area, hunting wildlife has become a source of protein supplementation and income for local minorities; it is therefore important to China and Myanmar to set up an intergovernmental investment fund for payments for ecosystem services, developing sustainable alternative livelihoods, and community co-management projects, improving financial support to the protected areas for their effective operation and capacity building, and enhancing environmental education for local people and park staffs.

As a supplementary note we also suggest that the distribution maps produced here should be superimposed with existing and future land-use maps for both the development departments of China and Myanmar to prevent future damage of the stretches of habitat that are key for the conservation of $R$. strykeri.

\subsection{Determining new investigation areas}

Another contribution of our study is to determine where the monkeys may occur for future field survey. Further population investigations should be conducted in the core habitats which have not been investigated and monitored. According to 
MAXENT, for example, field census or interview based surveys should be conducted in the core habitat between the proposed corridors of $\mathrm{C} 1$ and C2 (Fig. 2) which has a great potential to sustain some $R$. strykeri populations. Besides, the peripheral population in marginal habitats are probably more subject to habitat loss and more vulnerable to extinction before conservationists can find them. Accordingly, the northernmost habitat (Fig. 2, black circled area NO. M1), the Imawbum Mountain (black circled area NO. M2), and the southernmost habitat (black circled area NO. M4) need immediate field censuses to confirm the potential existence of peripheral populations.

\subsection{Approach caveats}

There probably are some prediction errors resulting from insufficient information on habitat. The elevational range of the core habitats is strongly associated with the mid-montane moist evergreen broad-leaved forest and coniferous broadleaved mixed forest ( $\mathrm{Li}$ et al., 2000). We found that $R$. strykeri prefers the abovementioned forest types but avoids secondary deciduous broad-leaved forest, secondary bamboo forest, artificial pine forest and coppice lands. These non-preferred forests have mostly been degraded and fragmented by large scale logging, road creation and burning or Lisu and Law Waw peoples' forest-crop rotation on these lands (eg. Fig. 3, black circled area NO. M3). We did not consider any of these forests in this study due to the limitation of ground-truth data for forest mapping. Additionally, the woodland being used in forest mapping includes shrub land, thus contains some non-habitats for the arboreal $R$. strykeri. Therefore, the entire habitat range could eventually be overrated and the habitat loss rate underestimated. A fine-scale vegetation type map of the distribution of $R$. strykeri, where possible, should be considered. Moreover, very informative materials are also essential to catch the typically patchy distribution of intense anthropogenic impacts, which in our study case include dam construction, mining sites, road opening and human settlements. 


\section{Conclusion}

As the black snub-nosed monkey is endemic to the junction of two biodiversity hotspot regions, Indo-Burma and Mountains of Southwest China (Marchese, 2015), we believe that, to protect this critically endangered species, all of its actual and potential distribution area should be strictly protected by banning hunting, logging, agricultural reclamation and other improper activities. As an umbrella and global flagship species, the effective conservation of $R$. strykeri will also protect other sympatrically threatened biota (see Tab. A.3). Results from this work highlighted that strengthening current conservation practices should ensure the long survival of R. strykeri in China whilst establishment of cross-border conservation and the rapid elimination of the threat in Myanmar are necessary for re-emergence of this species in that country and across the border. The conservation framework proposed in this paper therefore can serve as a basic prop for conservation department to formulate more specific strategies to protect $R$. strykeri. 


\section{ACKNOWLEDGMENTS}

This research complied with the policies and guidelines of the Australian National University and Dali University for the ethical treatment of primates. Funding was provided by the Zoological Society for the Conservation of Species and Populations (Germany, 7.Rhinopithecus.MMR.2015) and National Science Foundation of China (31560599). The authors were supported during this project by the Nujiang Forestry Department and the Gaoligong Mountains National Nature Reserve. Thanks are due to Emeritus Professor Colin Groves for his valuable suggestions on this paper and his help in English editing; three anonymous reviewers provided constructive comments to improve the original manuscript, and Frank Momberg and Guy Michael Williams (FFI, Myanmar) shared with us their knowledge and research outcomes on the species in Myanmar.

\section{REFERENCES CITED}

Aung, U.M., 2007. Policy and practice in Myanmar's protected area system. J. Environ. Manage. 84, 188-203.

Araújo, M.B., \& Peterson, A.T., 2012. Uses and misuses of bioclimatic envelope modeling. Ecology, 93, 1527-1539.

Araújo, M.B., Pearson, R.G., Thuiller, W., Erhard, M., 2005. Validation of species-climate impact models under climate change. Glob Chang Biol. 11, 1504-1513.

Breiman, L., 2001. Random forests. Mach Learn. 45, 5-32. 
Boubli, J.P., De Lima, M.G., 2009. Modeling the geographical distribution and fundamental niches of Cacajao spp. and Chiropotes israelita in Northwestern Amazonia via a maximum entropy algorithm. Int. J. Primatol. 30, 217-228.

Campos, F.A., Jack, K.M., 2013. A potential distribution model and conservation plan for the critically endangered Ecuadorian capuchin, Cebus albifrons aequatorialis. Int. J. Primatol. 34, 899-916.

Chaplin, G., 2005. Physical geography of the Gaoligong Shan area of southwest China in relation to biodiversity. Proc. Calif. Acad. Sci. 56, 527-556.

Chetan, N., Praveen, K.K., Vasudeva, G.K., 2014. Delineating Ecological Boundaries of Hanuman Langur Species Complex in Peninsular India Using MAXENT Modeling Approach. PloS one 9, e87804.

Cilliers, D., Evans, S., Coetzee, H., van Rensburg, L., 2013. Developing a site selection tool to assist reintroduction efforts for the Southern Ground-Hornbill Bucorvus leadbeateri. Ostrich 84, 101-111.

Cui, L.W., Li, Y.C., Li, J.F., He, X.Y., Ma, C., Scott, M.B., Li, D.H, Sun, J., Sun, W.M. Xiao, W., 2015. Distribution and conservation status of Shortridge's capped langurs Trachypithecus shortridgei in China. Oryx 50: 732-741.

Geissmann, T., Lwin, N., Aung, SS., Aung, TN., Aung, ZM., Hla, TH., Grindley, M., Momberg, F., 2011. A new species of snub-nosed monkey, genus Rhinopithecus Milne-Edwards, 1872 (Primates, Colobinae), from northern Kachin state, northeastern Myanmar. Am. J. Primatol. 73: 96-107.

Geissmann, T., Momberg, F. Whitten, T., 2012. Rhinopithecus strykeri. The IUCN Red List of Threatened Species 2012: e.T13508501A13508504. http://dx.doi.org/10.2305/IUCN.UK.2012-1.RLTS .T13508501A13508504.en (accessed 16.03.24). 
Giovanelli, J.G.R., Siqueira, M.F.D., Haddad, C.F.B., Alexandrino, J., 2010.

Modeling a spatially restricted distribution in the neotropics: how the size of calibration area affects the performance of five presence-only methods. Ecol. Modell. 221, 215-224.

Hernandez, P.A., Graham, C.H., Master, L.L., Albert, D.L., 2006. The effect of sample size and species characteristics on performance of different species distribution modeling methods. Ecography 29, 773-785.

Hernandez, P.A., Franke, I., Herzog, S.K., Pacheco, V., Paniagua, L., Quintana, H.L., Soto, A., Swenson, J.J., Tovar. C., Valqui, T.H., Vargas, J., Young, B.E., 2008. Predicting species distributions in poorly-studied landscapes. Biodivers. Conserv. 17, 1353-1366.

Hijmans, R.J., Cameron, S.E., Parra, J.L., Jones, P.G. Jarvis, A., 2005. Very high resolution interpolated climate surfaces for global land areas. Int. J. Climatol. $25,1965-1978$.

Hijmans, R.J., 2016. Raster: Geographic Data Analysis and Modeling. R package version $2.5-8$.

Hijmans, R.J., Phillips, S., Leathwick, J., Elith, J., 2016. dismo: Species Distribution Modeling. R package version 1.1-1.

Illera, J.C., Von Wehrden, H., Wehner, J., 2010. Nest site selection and the effects of land use in a multi-scale approach on the distribution of a passerine in an island arid environment. J. Arid Environ. 74, 1408-1412.

Ingberman, B., Fusco-Costa, R. and de Araujo Monteiro-Filho, E.L., 2016. A Current Perspective on the Historical Geographic Distribution of the Endangered Muriquis (Brachyteles spp.): Implications for Conservation. PloS one. 11. p.e0150906.

Li, H., Guo, H.J., Dao, Z.L., 2000. Flora of Gaoligong mountains. Science Press, Beijing. pp. 6-46. 
Liaw, A., Wiener, M., 2002. Classification and regression by random forest. R news, 2, 18-22.

Liu, F., McShea, W.J., Li, D., 2016. Correlating habitat suitability with landscape connectivity: A case study of Sichuan golden monkey in China. Ecol. Model. doi:10.1016/j.ecolmodel.2016.09.004

Long, Y., Momberg, F., Ma, J., Wang, Y., Luo, Y., Li, H., Yang, G., Li, M., 2012. Rhinopithecus strykeri found in China!. Am. J. Primatol. 74, 871.

Luo, Z., Yu, H., Pu, Y., Yang, J., Mei, H., Wang, D., Zhu, Z., Zhao, M., Wu, H., 2016. Assessment of Habitat Fragmentation and Corridors for an Isolated Subspecies of the Sichuan Golden Snub-Nosed Monkey, Rhinopithecus roxellana hubeiensis. Int. J. Primatol. 37, 438-459.

Ma, C., Luo, Z., Liu, C., Orkin, J.D., Xiao, W., Fan, P., 2015. Population and Conservation Status of Indochinese Gray Langurs (Trachypithecus crepusculus) in the Wuliang Mountains, Jingdong, Yunnan, China. Int. J. Primatol. 36, 749-763.

Ma, C., Huang, ZP, Zhao, XF., Zhang, LX., Sun, WM., Scott, MB., Wang, XW., Cui, LW., Xiao, W., 2014. Distribution and conservation status of Rhinopithecus strykeri in China. Primates 55, 1-6.

Marchese, C., 2015. Biodiversity hotspots: A shortcut for a more complicated concept. Global Ecol. Conserv. 3, 297-309.

Meijaard, E., Mengersen, K., Buchori, D., Nurcahyo, A., Ancrenaz, M., Wich, S., Atmoko, S.S.U., Tjiu, A., Prasetyo, D., Nardiyono, Hadiprakarsa, Y., Christy, L., Wells, J., Albar, G., Marshall, A.J., 2011. Why don't we ask? A complementary method for assessing the status of great apes. PloS one. 6, e18008. 
Meyer, D., Matauschek, C., Momberg, F., Roos, C., 2015. Preliminary Status Review of Leaf Monkeys in Myanmar. Fauna Flora International, Yangon, Myanmar \& German Primate Center, Göttingen, Germany. 38P.

Momberg, F., Lwin, N., Geissmann, T., 2010. Report on a snub-nosed monkey and biodiversity field survey, April 24-May 8, 2010. Yangon: Myanmar Primate Conservation Program.16p.

Peck, M., Thorn, J., Mariscal, A., Baird, A., Tirira, D., Kniveton, D., 2011.Focusing conservation efforts for the critically endangered brown-headed spider monkey (Ateles fusciceps) using remote sensing, modeling, and playback survey methods. Int. J. Primatol. 32, 134-148.

Phillips, S.J., Dudík, M., 2008. Modeling of species distributions with MAXENT: new extensions and a comprehensive evaluation. Ecography 31, 161-175.

Rao, M., Rabinowitz, A., Khaing, S.T., 2002. Status Review of the Protected-Area System in Myanmar, with Recommendations for Conservation Planning. Conserv. Biol. 16 360-368.

Schaffer-Smith, D., Swenson, J.J., Bóveda-Penalba, A.J., 2016. Rapid conservation assessment for endangered species using habitat connectivity models. Environ. Conserv. 43, 221-230.

Thorn, J.S., Nijman, V., Smith, D., Nekaris, K.A.I., 2009. Ecological niche modelling as a technique for assessing threats and setting conservation priorities for Asian slow lorises (Primates: Nycticebus). Divers. Distrib. 15, 289-298

Turvey, S.T., Trung, C.T., Quyet, V.D., Nhu, H.V., Thoai, D.V., Tuan, V.C.A., Hoa, D.T., Kacha, K., Sysomphone, T., Wallate, S., Hai, C.T.T., Thanh, N.V., Wilkinson, N.M., 2015. Interview - based sighting histories can inform regional conservation prioritization for highly threatened cryptic species. J. Appl. Ecol. 52, 422-433. 
Urbina-Cardona, J.N., \& Loyola, R.D., 2008. Applying niche-based models to predict endangered-hylid potential distributions: are neotropical protected areas effective enough. Trop. Conserv. Sci. 1, 417-445.

Yang, Y., Tian, Y., He, C., Huang, Z., Dong, S., Huang, Z., Wang, B., Li, G., Xiang, Z., Long, Y., Xiao, W., 2016. The Critically Endangered Myanmar snub-nosed monkey Rhinopithecus strykeri found in the Salween River Basin, China. Oryx 1-3. doi:10.1017/s0030605316000934

\section{Biosketches}

Guopen REN is a College Associate Professor based at the Institute of Eastern-Himalaya Biodiversity Research, Dali University. His work specializes in remote sensing, GIS, spatial ecology and their applications in biodiversity and conservation management.

Yin YANG is a PhD student at the School of Archaeology \& Anthropology, Australian National University with research interests in understanding the ecology and conservation needs for the black snub-nosed monkey in the Gaoligong Mountains Region.

Author contributions: WX designed the study. GPR, YY, WW and GY conducted data analysis. XDH, GSL, ZPH and CM collected species occurrence data. YY wrote the first draft, WX, GPR and YY revised the manuscript, and all authors made extensive contributions to the text. 
Table 1. Hierarchical definition of forests

\begin{tabular}{cl}
\hline \multicolumn{1}{c}{ Name } & \multicolumn{1}{c}{ Definition } \\
\hline Fs: forest + shurb & Tree crown cover degree $>40 \%$, including forest and shrub. \\
Fw: forest $=$ Fc + Fo & Tree crown height $>=3 \mathrm{~m}$ \\
Fc: closed-forest & Tree crown cover degree $>=70 \%$ \\
Fo: open-forest & $40 \%=<$ Tree crown cover degree $<70 \%$ \\
Sh: shrub & Plant cover degree $>=40 \%$, but not fulfilling the other \\
& conditions of forests \\
\hline
\end{tabular}


Table 2. Habitat quality levels description of black snub-nosed monkeys

\begin{tabular}{lll}
\hline Quality & $\begin{array}{l}\text { Predicted } \\
\text { value }\end{array}$ & Description \\
\hline Core & $>0.50$ & Equal training sensitivity and specificity $(0.50)$ \\
Medium & $0.41-0.50$ & Maximum training sensitivity plus specificity $(0.41)$ \\
Edge & $0.04-0.41$ & Minimum training presence data omission $(0.04)$ \\
Non-habitat & $<0.04$ & Less than 0.1\% of training presence data predicted $(0.04)$ \\
\hline
\end{tabular}




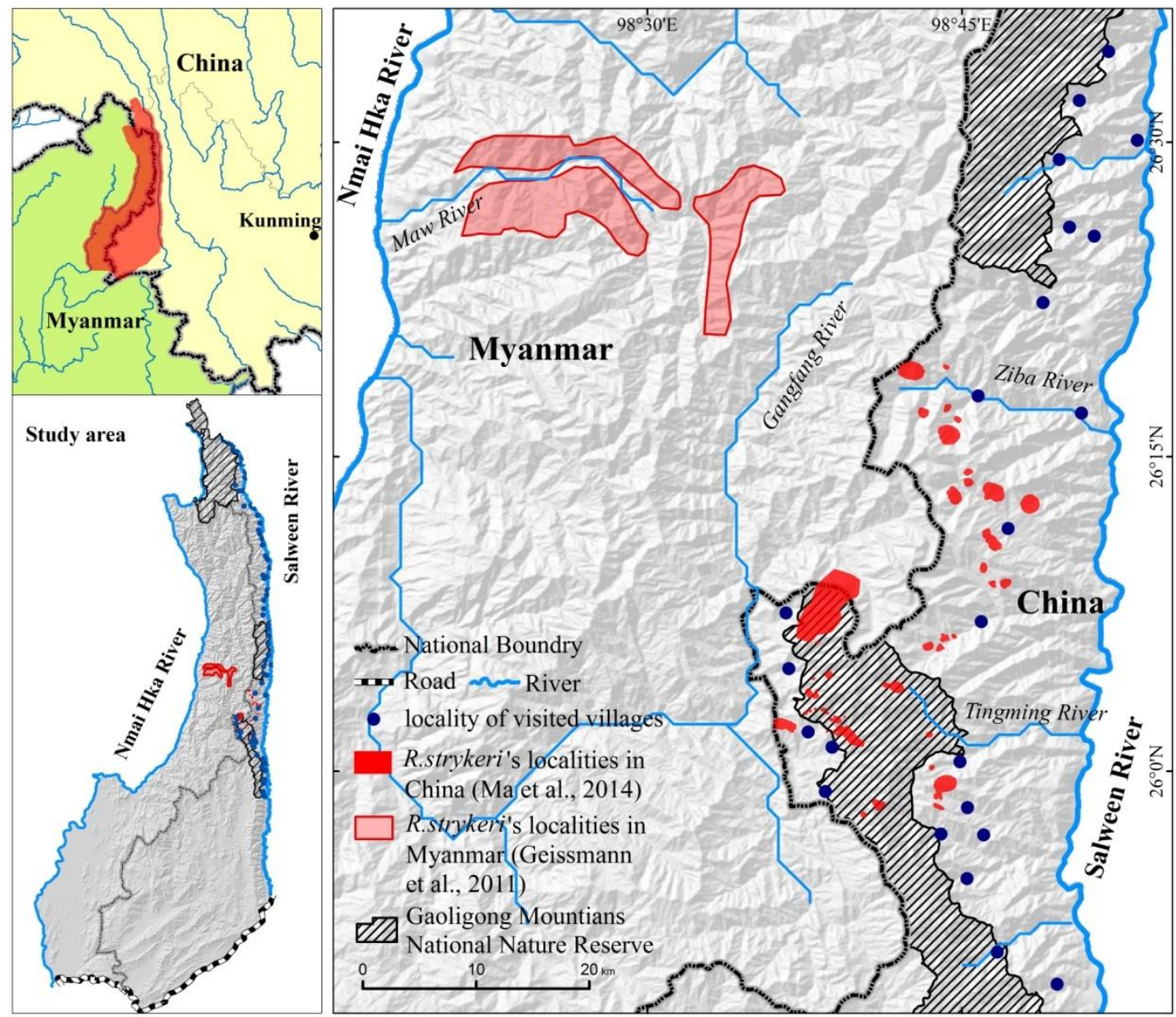

Figure 1. Map of the study area and distribution of $R$. strykeri in the Sino-Myanmar border region. 


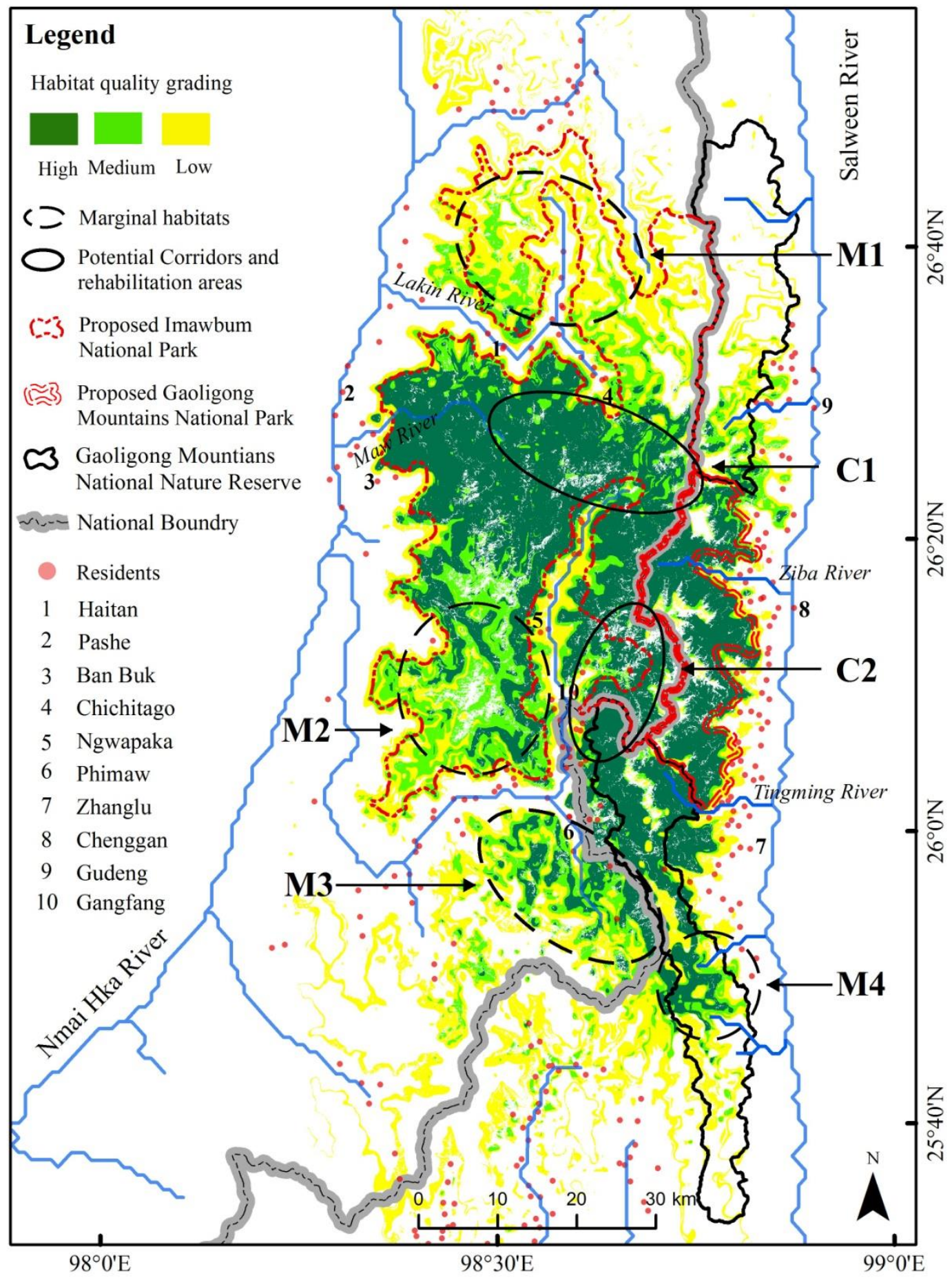

Figure 2. Predictive habitat distribution and quality map with proposed conservation and management areas for $R$. strykeri in the Sino-Myanmar border region according to climate niche analysis, forest cover in 2015 and MAXENT. 


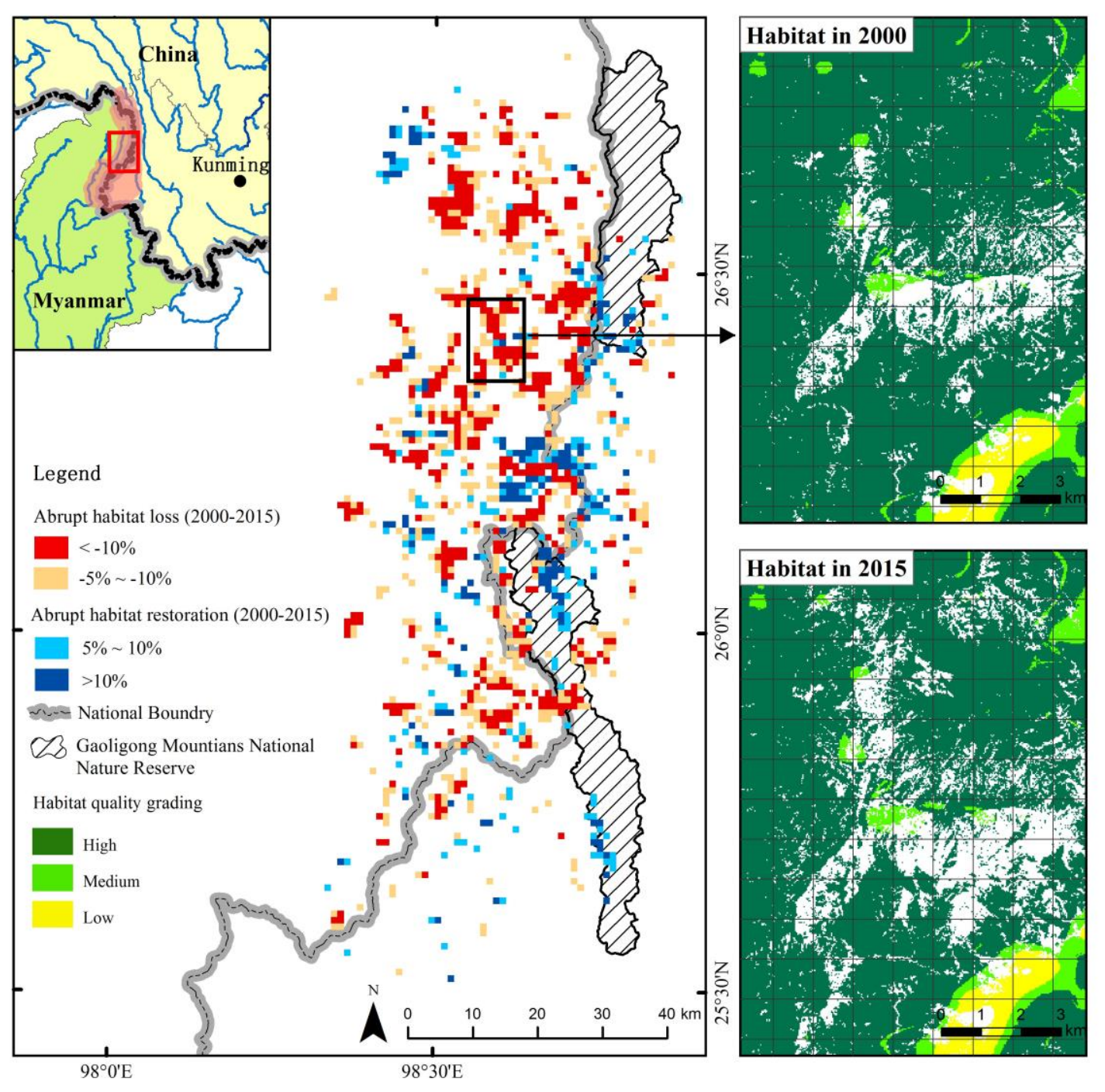

Figure 3. Habitat alterations (2000-2015) in the Sino-Myanmar border region, measured as the percentage of habitat cover change within $1 \times 1 \mathrm{~km}^{2}$ grid cells. The locations of habitat loss are marked with red colours and rehabilitation with blue colours. The right-hand images show an example of habitat loss, fragmentation and insularization in the study area during 2000 and 2015. 